Section Editor

Mitchell S.V. Elkind,

MD, MS

Journal Club:

\title{
Surveillance neuroimaging and neurologic examinations affect care for intracerebral hemorrhage
}

Stephanie M. Stahl, MD Jason Mackey, MD, MS

Correspondence to Dr. Stahl: smtieken@iupui.edu
The article "Surveillance neuroimaging and neurologic examinations affect care for intracerebral hemorrhage" is reviewed. This review focuses on the methods, results, limitations, and merits of the original article.

BACKGROUND AND SIGNIFICANCE Despite advances in medical care, the morbidity and mortality of intracerebral hemorrhage $(\mathrm{ICH})$ remains high. ${ }^{2}$ Early neurologic worsening occurs in about one-third of patients with $\mathrm{ICH} .{ }^{3}$ Delayed intraventricular hemorrhage (IVH) is common and independently associated with morbidity and mortality. ${ }^{4}$ In the STICH trial, $26 \%$ of patients initially randomized to medical management subsequently required surgery, largely due to clinical/neurologic deterioration or hematoma expansion. ${ }^{5}$ Neurocritical care reduces in-hospital mortality rates, ${ }^{6}$ but the degree of surveillance necessary to improve outcomes remains unclear. Data are limited on surveillance imaging and clinical examinations in $\mathrm{ICH}$, and the guidelines are not detailed on this issue.

HYPOTHESIS AND DESIGN In this single-center prospective observational cohort study of 239 patients, the authors sought to evaluate whether surveillance neuroimaging and repeat neurologic examinations affect care in patients with $\mathrm{ICH} .{ }^{1}$ Identifying any method to improve patient outcomes is important given the high morbidity and mortality of ICH. Via extensive chart review, the authors stratified patients who underwent surgical intervention either at initial evaluation or later in the hospital course. In the latter group, the authors evaluated whether a change in neuroimaging or neurologic examination led to the intervention. A secondary analysis attempted to identify predictors of subsequent surgical intervention.

METHODS Patients with spontaneous ICH were prospectively enrolled over a 5-year period at a single academic center. Those with ICH secondary to trauma, structural lesions, hemorrhagic transformation of ischemic stroke, or vascular malformations were excluded.

Patients underwent noncontrast head CT (HCT) scans at intervals of 6, 24, and 48 hours after the initial brain imaging. After 48 hours, HCT was repeated on a daily basis for patients at high risk for deterioration.
An emergent HCT was performed outside of the sequence of scheduled repeat scans in patients with a change in status. The protocol was stopped or deferred in those patients too medically unstable to have a scan and in those for whom withdrawal of care had been decided.

The Glasgow Coma Scale (GCS) was performed at admission and on an hourly basis by a neuroscience nurse throughout the intensive care unit (ICU) stay, and the NIH Stroke Scale (NIHSS) was performed by a neuroscience nurse at admission and 12 hours after admission. A physician was notified of changes in neurologic status. In addition, all patients were examined at least twice daily by neurologists, neurosurgeons, or critical care physicians with experience in neurologic conditions. A certified examiner recorded the NIHSS score and the modified Rankin Scale (mRS) score at 14 days or at discharge (whichever came first). The mRS was repeated at 28 days and 3 months via a validated questionnaire.

Craniotomies for hematoma evacuation \pm decompression or ventriculostomies for hydrocephalus or IVH were recorded if performed. Craniotomies were typically performed in patients with either a large $(>30$ $\mathrm{mL}$ ) superficial lobar hemorrhage (with concern for life-threatening mass effect) or a cerebellar hemorrhage (with concern for brainstem compression or ventricular obstruction). Ventriculostomies were typically performed in patients with hydrocephalus or IVH and diminished level of consciousness. The chart was reviewed in each of these cases to identify what clinical and objective findings led to the intervention. If the intervention was performed as soon as able after the initial assessment, the case was judged as related to initial management. If the intervention was performed later, it was judged as either scan-initiated or examinationinitiated. Analyses comparing scan-initiated vs examination-initiated interventions were performed using the Fisher exact test. To assess for predictors of subsequent surgical intervention, the authors identified variables associated with subsequent intervention on univariate analysis and then entered variables with $p<$ 0.2 into a logistic regression model to identify independent predictors. A threshold $p$ value of 0.2 is commonly

From the Department of Neurology, Indiana University School of Medicine, Indianapolis.

Go to Neurology.org for full disclosures. Funding information and disclosures deemed relevant by the authors, if any, are provided at the end of the article. 
used for identifying potentially important variables for further multivariate analysis.

RESULTS Eighty-four patients (35\% of the 239 patients) underwent 88 discrete surgical interventions, including 52 ventriculostomies, 21 craniotomies, and 11 craniotomies with concurrent ventriculostomies. Sixty-four $(73 \%)$ of the interventions occurred due to the initial evaluation and 24 (27\%) occurred due to subsequent evaluations. The median time in which the subsequent surgical interventions occurred was 15.9 hours (interquartile range 8.9-27.0) from symptom onset. Intervention was delayed in 3 cases (2 due to surrogate decision-making delay and 1 due to a logistical reason), and these cases were classified as initial management interventions due to intent of the medical team. Eleven (46\%) of the subsequent interventions were scan-initiated and 13 (54\%) were examination-initiated $(p=0.8)$.

No demographic, radiologic, or clinical findings at the time of initial evaluation were independently associated with subsequent intervention on multivariate analysis. The ICH score was associated with a need for subsequent surgical intervention $(p=0.045$ in the univariate analysis, but $p=0.30$ in the multivariate). Delayed IVH $(p=0.005)$ and hematoma expansion $(p<0.001)$ on surveillance neuroimaging were associated with subsequent surgical intervention.

INTERPRETATION This study demonstrates that surveillance neuroimaging and serial neurologic examinations identified cases in which subsequent surgical intervention was indicated. The structured program led to subsequent surgical intervention in about $10 \%$ of the total number of enrolled patients. The study results are potentially applicable at both patient and health care systems levels. Possibilities range from alterations in neurologic ICU design (e.g., mobile CT scanners in the ICU) to workforce adjustments (e.g., additional neuroscience-trained nurses), among others.

There are limitations to this study. The study does not address how many patients had neuroimaging changes or examination changes or the proportion leading to subsequent surgical intervention. Outcomes are not reported. According to the methods, mRS was recorded at various intervals but the results are not reported. The number and timing of deaths in each category (no intervention, initial intervention, and subsequent intervention) would be interesting to evaluate in light of the "self-fulfilling prophecy" phenomenon. ${ }^{8}$ A detailed examination of the outcomes exceeds the scope of the article, and the authors point out the objective of this study was not to determine the efficacy of the surgical interventions. ICH location (e.g., deep, lobar, or infratentorial) and stratification of $\mathrm{ICH}$ volumes by location are not reported. The authors do not offer a hypothesis for why variables at initial presentation did not predict the need for delayed intervention. The authors also do not comment specifically on which examination instruments (GCS, NIHSS) prompted delayed interventions.

While repeat neurologic examinations are relatively easy to obtain with minimal cost and risk to the patient, repeat HCT scans increase the cost and radiation exposure to the patient. Relatively few HCTs led to a surgical intervention and, as the authors state, whether subsequent neurologic examination would have identified the deterioration requiring intervention is unknown, as is the impact of any delay.

This study demonstrates that a structured imaging and examination program can affect $\mathrm{ICH}$ care and is an important addition to the field. Whether the benefits outweigh the risks and costs of such a program requires further work.

\section{AUTHOR CONTRIBUTIONS}

Stephanie Stahl: drafting/revising the manuscript, analysis/interpretation of data. Jason Mackey: revising the manuscript, analysis/interpretation of data.

\section{STUDY FUNDING}

No targeted funding reported.

\section{DISCLOSURE}

S. Stahl reports no disclosures. J. Mackey is funded by the NIH Loan Repayment Program, the IU Health Values Fund (VFR-365), and the CTSI Project Development Team (NIH/NCRR RR025761) for ICH research and has served as an expert witness in stroke cases. Go to Neurology.org for full disclosures.

\section{REFERENCES}

1. Maas MB, Rosenberg NF, Kosteva AR, et al. Surveillance neuroimaging and neurologic examinations affect care for intracerebral hemorrhage. Neurology 2013;81:107-112.

2. Flaherty ML, Haverbusch $M$, Sekar $P$, et al. Long-term mortality after intracerebral hemorrhage. Neurology 2006; 66:1182-1186.

3. Leira R, Dávalos A, Silva Y, et al. Early neurologic deterioration in intracerebral hemorrhage: predictors and associated factors. Neurology 2004;63:461-467.

4. Maas MB, Nemeth AJ, Rosenberg NF, Kosteva AR, Prabhakaran S, Naidech AM. Delayed intraventricular hemorrhage is common and worsens outcomes in intracerebral hemorrhage. Neurology 2013;80:1295-1299.

5. Mendelow AD, Gregson BA, Fernades HM, et al. Early surgery versus initial conservative treatment in patients with spontaneous supratentorial intracerebral haematomas in the International Surgical Trial in Intracerebral Haemorrhage (STICH): a randomised trial. Lancet 2005;365:387-397.

6. Suarez JI. Outcome in neurocritical care: advances in monitoring and treatment and effect of a specialized neurocritical care team. Crit Care Med 2006;34:S232-S238.

7. Morgenstern LB, Hemphill JC III, Anderson C, et al. Guidelines for the management of spontaneous intracerebral hemorrhage: a guideline for healthcare professionals from the American Heart Association/American Stroke Association. Stroke 2010;41:2108-2129.

8. Becker KJ, Baxter AB, Cohen WA, et al. Withdrawal of support in intracerebral hemorrhage may lead to selffulfilling prophecies. Neurology 2001;56:766-772. 


\title{
Neurology
}

\author{
Journal Club: Surveillance neuroimaging and neurologic examinations affect care for \\ intracerebral hemorrhage \\ Stephanie M. Stahl and Jason Mackey \\ Neurology 2014;82;e108-e109 \\ DOI 10.1212/WNL.0000000000000259
}

\section{This information is current as of March 31, 2014}

Updated Information \& Services

References

Subspecialty Collections

Permissions \& Licensing

Reprints including high resolution figures, can be found at: http://n.neurology.org/content/82/13/e108.full

This article cites 8 articles, 6 of which you can access for free at: http://n.neurology.org/content/82/13/e108.full\#ref-list-1

This article, along with others on similar topics, appears in the following collection(s):

CT

http://n.neurology.org/cgi/collection/ct

Intracerebral hemorrhage

http://n.neurology.org/cgi/collection/intracerebral_hemorrhage

Information about reproducing this article in parts (figures,tables) or in its entirety can be found online at:

http://www.neurology.org/about/about_the_journal\#permissions

Information about ordering reprints can be found online:

http://n.neurology.org/subscribers/advertise

Neurology ${ }^{\circledR}$ is the official journal of the American Academy of Neurology. Published continuously since 1951, it is now a weekly with 48 issues per year. Copyright (O) 2014 American Academy of Neurology. All rights reserved. Print ISSN: 0028-3878. Online ISSN: 1526-632X.

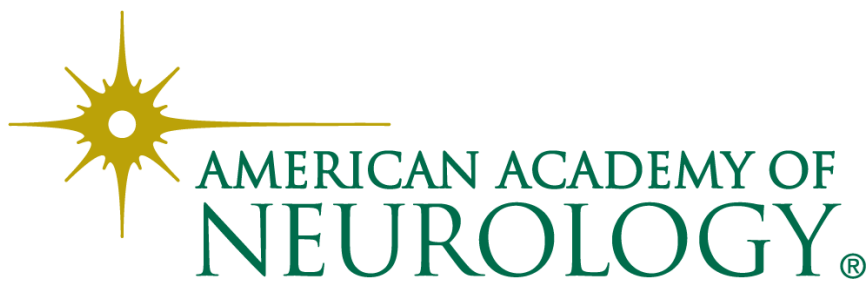

